\title{
A rare cause of non-discogenic sciatica; musculus gemellus inferior: A case report
}

\author{
Arzu Atıc1, ${ }^{1}$ Duygu Geler Külcü, ${ }^{2}$ Pinar Akpınar, ${ }^{1}$ Deniz Akay Urgun ${ }^{3}$ \\ ${ }^{1}$ Department of Physical Medicine and Rehabilitation, Fatih Sultan Mehmet Training and Research Hospital, İstanbul, Turkey \\ ${ }^{2}$ Department of Physical Medicine and Rehabilitation, Haydarpasa Numune Training and Research Hospital, İstanbul, Turkey \\ ${ }^{3}$ Department of Radiology, Fatih Sultan Mehmet Training and Research Hospital, İstanbul, Turkey
}

Received: June 2016 Accepted: June 2016

\begin{abstract}
Herein, we report a 51-year-old female with complaint of right sciatica. According to physical examination, the etiology was suspected as piriformis syndrome. Therefore, piriformis injection was administered and piriformis stretching exercises were recommended.However the complains did not resolve. Magnetic resonance imaging showed hyperintensity of the right inferior musculus gemellus. One of the main causes of extra-spinal sciatica is piriformis syndrome. However, other pelvic muscles anatomically near the sciatic nerve are often overlooked. Magnetic resonance imaging is useful in the differential diagnosis from intractable piriformis syndrome, particularly in cases resistant to treatment.
\end{abstract}

Keywords: Magnetic resonance imaging; musculus gemellus inferior; non-discogenic sciatica; piriformis syndrome.

Extra-spinal causes of sciatic pain are usually underdiagnosed, as they are extremely rare. Herein, we report a female case of non-discogenic sciatica secondary to inflammation of the inferior musculus gemellus.

\section{CASE REPORT}

A 51-year-old female was admitted to our outpatient clinic with a chief complaint of right sciatica. She reported an increase in the pain intensity by sitting for prolonged periods and walking with discomfort continuing through the night. On physical examination, the straight leg raise test result was negative. The strength of all muscles of the lower extremities and deep tendon reflexes were normoactive. She exhibited hypoesthesia of the right leg at the L2, L3, L4, L5, and S1 dermatomes. Lumbosacral anteroposterior/lateral X-ray revealed no pathology of the lumbar spine or sacroiliac joint. There was no indication of root compression or herniation on magnetic resonance imaging (MRI) of the lumbar region. Also, there was no pathological indication of sacroiliac joint dysfunction. Electromyography showed no radiculopathy. As the flexion, adduction, internal rotation (FAIR) test was

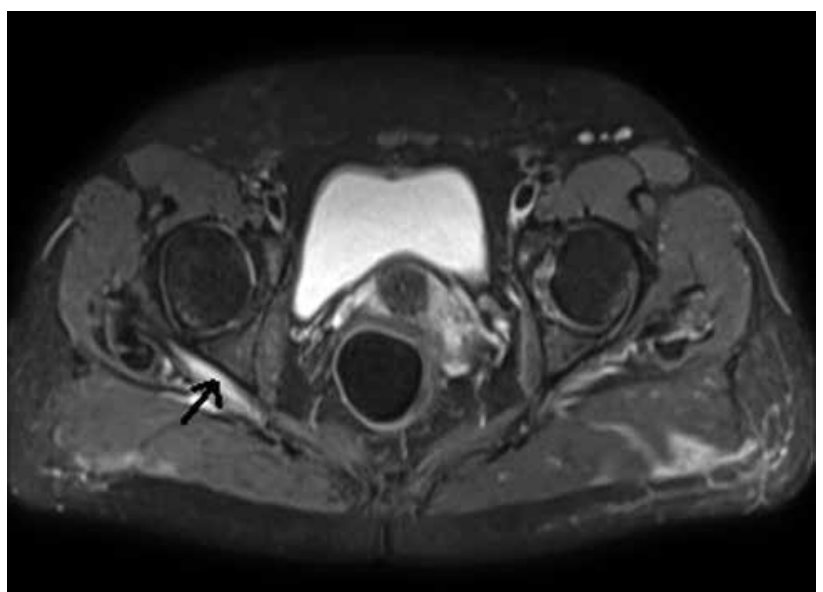

Figure 1. Axial $\mathrm{T}_{2}$-weighted magnetic resonance imaging of the inferior abdomen showing hyperintensity of the right inferior musculus gemellus.

Corresponding author: Arzu Atıcı, MD. Fatih Sultan Mehmet Eğitim ve Araştırma Hastanesi Fiziksel Tıp ve Rehabilitasyon Kliniği, 34752 İçerenköy, Ataşehir, İstanbul, Turkey. e-mail: arzususinatici@gmail.com 
positive and there was tenderness with deep palpation of the gluteal region, the etiology was suspected as piriformis syndrome. Therefore, piriformis injection was administered under ultrasonography $(1 \mathrm{~mL} / 7 \mathrm{mg}$ betamethasone and $4 \mathrm{~mL}$ of $2 \%$ lidocaine). Piriformis stretching exercises were recommended to the patient, and pain began to slightly decrease for a few days, but then increased again. The Visual Analog Scale (VAS) score was 10. Inferior abdominal MRI was acquired to disclose any pathology, which may have compressed the sciatic nerve. An axial $\mathrm{T}_{2}$-weighted image showed increased intensity of the inferior gemelli muscle (Figure 1). Diclofenac potassium (50 mg, three times daily), pregabalin $150 \mathrm{mg}$ twice a day (week 1: $75 \mathrm{mg}$ two times daily, and then $150 \mathrm{mg}$ two times daily), and a combination of tramadol and paracetamol (37.5 mg/325 mg) were prescribed to be used, if necessary. Her complaint resolved after six months with a VAS score of 0 .

\section{DISCUSSION}

There are several etiologies of extra-spinal sciatica that include traumatic, infective (e.g. psoas abscess) and inflammatory (sacroiliitis) causes, tumor growth, vascular anomalies, endometriosis, and piriformis syndrome. ${ }^{[1]}$ One of the main causes of extra-spinal sciatica is piriformis syndrome. ${ }^{[2]}$ However, other pelvic muscles anatomically near the sciatic nerve are often overlooked.

Murata et al. ${ }^{[3]}$ clearly observed by surgery and reported that stretching of the obturator internus muscle compressed the sciatic nerve. In another study by Meknas et al., ${ }^{[4]}$ six sciatica patients with suspected piriformis syndrome underwent surgery to relieve pressure on the sciatic nerve. The piriformis muscle and tendon were normal in the patients and the obturator internus muscle of each was very tense, slightly hyperemic and hypertrophic. Bano et al. ${ }^{[5]}$ also reported a case of a quadratus femoris tear in a patient presenting with persistent sciatica. Similar to these case reports, our patient developed sciatica due to inflammation of the musculus gemellus.

In conclusion, musculus gemellus abnormalities should be considered as one of the potential cause of sciatica. Magnetic resonance imaging is useful in the differential diagnosis of non-discogenic sciatica from intractable piriformis syndrome, particularly in cases resistant to medical treatment or injection.

\section{Declaration of conflicting interests}

The authors declared no conflicts of interest with respect to the authorship and/or publication of this article.

\section{Funding}

The authors received no financial support for the research and/or authorship of this article.

\section{REFERENCES}

1. Ergun T, Lakadamyali H. CT and MRI in the evaluation of extraspinal sciatica. Br J Radiol 2010;83:791-803.

2. Stewart JD. The piriformis syndrome is overdiagnosed. Muscle Nerve 2003;28:644-6.

3. Murata Y, Ogata S, Ikeda Y, Yamagata M. An unusual cause of sciatic pain as a result of the dynamic motion of the obturator internus muscle. Spine J 2009;9:e16-8.

4. Meknas K, Christensen A, Johansen O. The internal obturator muscle may cause sciatic pain. Pain 2003;104:375-80.

5. Bano A, Karantanas A, Pasku D, Datseris G, Tzanakakis G, Katonis P. Persistent sciatica induced by quadratus femoris muscle tear and treated by surgical decompression: a case report. J Med Case Rep 2010;4:236. 